change, Monmonier juxtaposes two charts of the Outer Banks of North Carolina that show how the coastline in this area has receded over the past 125 years. Turning to predictive cartography - that is, maps and charts that indicate the probable future effect of rising seas and coastal subsidence - he admits that their foundations incorporate "multiple sources of uncertainty". Monmonier acknowledges the sensitive political nature of materials of this type. For example, although he has seen the latest maps of tidal marshlands prepared by the US Environmental Protection Agency, he is prevented from discussing them before their authorized release.

By highlighting a selection of topics, Coast Lines may succeed in its goal of getting the public to think about what maps show and why. However, Monmonier cautions prospective navigators to be aware that modern global-positioning technology enables them to know their latitudes and longitudes with greater precision than the scientists who made their maps in the first place.

Deborah Jean Warner is curator of the physical sciences collections at the National Museum of American History, Smithsonian Institution, Washington DC 20013-7012, USA.

\title{
Changing perceptions of light
}

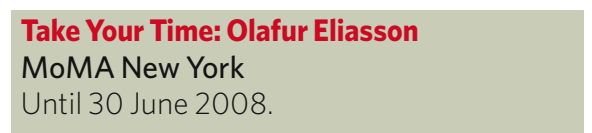

The vast foyer of New York's Museum of Modern Art (MoMA) is being dive-bombed by a small electric fan. Suspended from the ceiling by wire, it propels itself on an erratic course, buzzing over the spectators like a giant insect. Rather more calming is the title work of the current exhibition, Take Your Time, by the Danish-Icelandic artist Olafur Eliasson. It features a 12-metre-wide mirrored disc, positioned off-kilter so that as it slowly revolves it distorts the lines of the room. Hypnotic and unsettling, it is best experienced while lying on the floor.

Eliasson is an experimental artist who engages with science and the natural world. In 2003, he filled the immense Turbine Hall of London's Tate Modern gallery with a giant artificial sun made of 200 yellow lamps, mirrors and mist. Its warm glow induced crowds to recline on the gallery floor as if basking on a beach.

Fascinated by our perception of visual effects, Eliasson co-hosted a conference at Columbia University, New York, on 'The Colors of the Brain' to coincide with his 38-piece exhibition. The artist led his audience through an experiment designed to induce optical after-images, asking them to gaze into the bright lights overhead, then stare for a minute at a bottle placed on a chair, and then look at a blank screen. "The pink colour you see is the colour of blood in the eyes," he explained. Both scientists and art historians took part: neuroscientist David Eagleman discussed optical illusions and synaesthesia, and the string theorist Brian Greene made a valiant effort to explain his own abstract work.

"Science," Greene asserted, "reveals a reality different from what we perceive." Eliasson similarly questions our precarious notion of what is external and what is created in the mind of the perceiver. His $360^{\circ}$ Room For All Colours

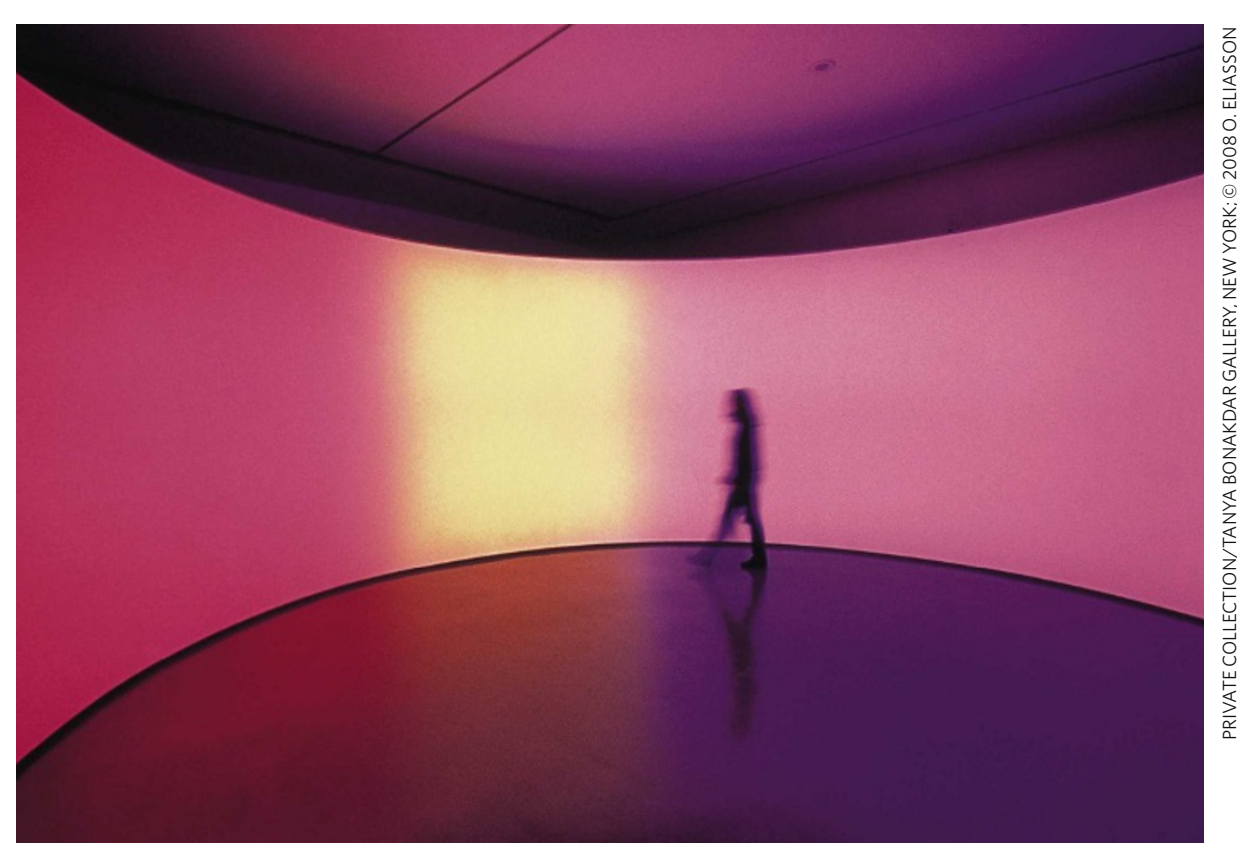

Olafur Eliasson's $360^{\circ}$ Room For All Colours explores how our minds perceive the external world.

— on view at MoMA - is a backlit drum of projected light that shines bright pink, bleeds to white, then turns electric blue. The colours seem to loiter in the mind's eye even after they have gone. Another room is starkly lit by flashes of different tones of white (some cool, others warm), the subtle changes in hue revealing the white cube gallery space to be less of a neutral background than it might initially appear.

Two rooms display Eliasson's maquettes and architectural models. Contrasting with the minimalist museum installations, these give us a glimpse inside Eliasson's working mind - the rooms are a crazy mix of revolving spheres, kaleidoscopes, geodesic domes and chandeliers made of shards of mirrored glass.

Much of Eliasson's work deals with the intersection of natural and mechanical elements. In Your Strange Certainty Still Kept, an aggressive strobe light freeze-frames water droplets as they sprinkle into a trough from a perforated hose. The stationary drops sparkle and glitter, as if suspended in space. In Beauty, gallery viewers may walk through a fiery, pulsating rainbow curtain of fine mist that is illuminated by a single spotlight. In Reversed Waterfall, a makeshift stack of metal bins, pumps and jets are assembled to force the water to flow uphill.

In late June, and on a different scale, the city's Public Art Fund will launch Eliasson's US\$15-million New York City Waterfalls project, a series of four enormous and noisy man-made torrents measuring between 27 and 37 metres high. They will be located under the Brooklyn Bridge and at other sites along the East River. It will be the largest art installation in the city since Christo filled Central Park with his saffron-coloured Gates in 2005 and, for the few days that this aqueous extravaganza coincides with his retrospective, Eliasson's dominance of New York's art scene will be total.

Christopher Turner is a writer based in New York. 